\title{
Tunnel Hull Design Project: Engaging Entry-Level Students in Vehicle De- sign with a Wing-in-Ground Effect Vessel Design Project
}

\section{Mr. Eric Leonhardt, Western Washington University}

I work with students to develop lightweight, high performance vehicles that often utilize hybrid or electric drivetrains. The vehicles often feature advances in materials-such as the carbon fiber honeycomb that we developed for impact attenuation-or advances in fuels. We built a pilot scale, biomethane or renewable natural gas facility at a dairy to power a local bus operator and our hybrid vehicles. I have used wingin-ground effect design projects to engage students in concepts of lift, drag, and how vehicle design parameters affect vehicle performance. 


\title{
Tunnel-Hull Design Project: Engaging Entry-Level Students in Vehicle Design with a Wing-in-Ground-Effect Vessel Design Project
}

\begin{abstract}
An entry-level vehicle design course, VHCL 260 Vehicle Systems I, uses a conceptual tunnelhull design project as a means to introduce students to forces and moments on vehicles and how they affect vehicle design. A tunnel-hull boat is a high-speed marine vessel that utilizes wing-inground effect to support a portion of the vehicle's weight. For this project, the vessel consists of two planing hulls that sandwich a central wing and is powered by outboard marine engines. The tunnel-hull design project introduces students to aerodynamic and hydrodynamic lift and drag. The project spans four weeks of a ten-week, introductory course primarily focused on internal combustion engines, electric motors and other prime movers of vehicles. Students alter vehicledesign parameters such as chord length, tunnel span, tunnel-hull beam, and deadrise angles, and perform calculations for lift, drag, and moments on their conceptual models. Students create a mathematical model that predicts vehicle performance. They then build representative scale physical models of their designs. This project, proposed as an alternative to traditional, entrylevel engineering projects, seeks to engage students in a design project early in their academic program. It was used in an introductory course as part of an overhaul of a vehicle-design curriculum. This paper outlines methods for replicating this project in other courses.
\end{abstract}

\section{Introduction}

Western Washington University's vehicle design program has undergone changes to meet the requirements for ABET accreditation and to provide students with the principles and practices of vehicle design at an earlier stage in their course of study. Formerly, the program's introductory vehicle course focused on internal combustion engines and other "prime movers" such as electric motors, while later courses introduced vehicle topics such as vehicle dynamics, chassis design, and aerodynamics. Before these program changes, students competing in SAE collegiate-design challenges such as Baja or Formula SAE designed vehicle systems and components prior to experiencing the appropriate formal coursework. The tunnel-hull design project plays a role in addressing the challenge these situations posed by introducing pre-major students to a vehicledesign process that includes calculations of fundamental vehicle forces.

The tunnel-hull design project grew out of an earlier design project developed for high-school and first-year engineering technology students who developed Ekranoplan or wing-in-groundeffect vehicles powered primarily with rubber bands. ${ }^{1}$ For the Ekranoplan project, the course introduced the basic concepts of lift, drag, and thrust; however, these were not used directly by students to calculate vehicle parameters or specifications. Instead, the students determined a maximum weight per lifting-body area metric $\left(\mathrm{N} / \mathrm{mm}^{2}\right)$ that enabled them to successfully build flying balsa-framed models. Students explored a wide variety of vehicle configurations and wing types, as pictured in Figure 1. 


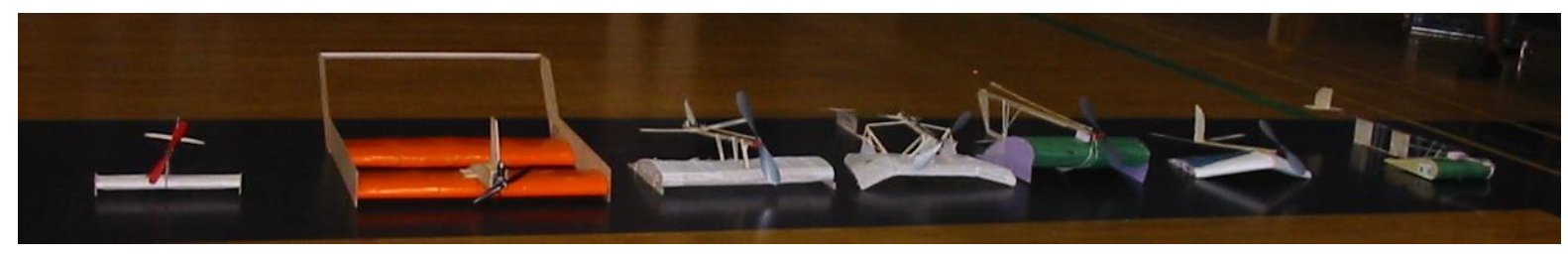

Figure 1. Prototype Ekranoplan vehicles ready for flight testing.

The tunnel-hull project differs in three ways from the Ekranoplan project. Second-year students attend the course with a calculus co-requisite. It is likely that they complete both calculus and physics before attending this course. Second, while both projects began with a discussion and development of requirements, the tunnel-hull project requires calculation, estimation and iterative solving to create a mathematical design model. Third, although students built a physical prototype for both projects, the tunnel-hull models are not currently robust enough to allow physical testing. A related difference is that the entry-level Ekranoplan project allowed a wide variety of potential designs, while the tunnel-hull project focuses on one vehicle configurationtwin hulls adjacent a central wing - to enable the calculation of performance by students who have completed pre-calculus. The detailed parameters of the vehicle are mathematically modeled and adjusted to meet a set of requirements outlined below. Prototype physical models are built to demonstrate the vehicle configuration, although the physical models are not yet flight-tested.

The project spans four weeks of a ten-week course. During the first two weeks of the project, students attend three lecture/lab sessions per week to learn the tunnel-hull conceptual design process. Each student builds a spreadsheet to model the parameters and performance of the proposed conceptual design. Time is allocated during each two-hour session of the class to assist the students with the construction of the spreadsheet. The spreadsheet is checked for effectiveness at a first-draft stage that includes all of the basic parameters, and the tool predicts initial vehicle performance. An evaluation of the spreadsheet at the end of the two-week period includes an iterative stability check of the design. In addition, students are quizzed to assess their understanding of each concept and calculation. Students construct a physical scale model of their design using primarily card stock material (used manila folders) or balsa wood. The physical model is due up to two weeks after the spreadsheet. Three one-hour lab sessions are used to assist students with the construction of their physical models. Completion of the physical model occurs outside scheduled class time during open lab hours. Students have lab access four days per week from 8 a.m. to 8 p.m. and 8 a.m. to 5 p.m. on Fridays.

The tunnel-hull design project is made possible by the work of James Russell, P.E., and explained in his book Secrets of Tunnel Boat Design. ${ }^{2}$ The book outlines the design process and the key parameters that impact tunnel-hull performance. It provides coefficients of lift and drag for the large-chord short-span wings operating in ground effect unique to tunnel boats. The book also provides hydrodynamic lift and drag coefficients for typical tunnel-hull forms and propulsion systems. The example design outlined below uses variable names and parameters, which the book provides. Russell also offers a software package to perform the analysis; this was not used for the class, as the goal was to help students understand the physics-based math model used to predict the tunnel hull's performance. 


\section{Design Process}

Students are given a target mission and asked to develop the design requirements for the tunnel hull. The initial mission was to develop a vehicle that could allow either two people or four-tosix people to travel roughly $145 \mathrm{~km}$ between Seattle and Bellingham, Washington, without rushhour traffic, a pilot's license, or speed limits. The parameters provided to students are listed in Table 1.

Table 1. Initial design requirements

\begin{tabular}{|l|l|l|}
\hline Requirements & "Sports Car" & "Van" \\
\hline Passengers & 2 & $4-6$ \\
\hline Cruising Speed & $153 \mathrm{kph}$ & $96 \mathrm{kph}$ \\
\hline
\end{tabular}

Students created an initial set of requirements to consider in the design, as sampled below in Table 2. Some of these requirements, such as the number of passengers, the storage, and the sleeping accommodations, affect the weight and size of the vehicle. Other requirements, such as trailerability and marina-based operation, impact the width and economic length of the vehicle. Noise limitations limited our consideration of propulsion to waterborne propellers. Many of the remaining requirements did not impact the initial conceptual design, since they did not impact the overall parameters of the vessel.

Table 2: Sample of student-created requirements

\begin{tabular}{|l|l|l|}
\hline Fuel Economy & $\begin{array}{l}\text { Sleeping } \\
\text { Accommodations }\end{array}$ & $\begin{array}{l}\text { Maneuverability-Low Speed } \\
\text { High Speed-Whale avoidance test }\end{array}$ \\
\hline $\begin{array}{l}\text { Advanced knowledge of } \\
\text { obstacles or potential } \\
\text { impact conditions }\end{array}$ & $\begin{array}{l}\text { Night operation } \\
\text { capability }\end{array}$ & Noise \\
\hline $\begin{array}{l}\text { Marine lighting and } \\
\text { other USCG } \\
\text { requirements }\end{array}$ & Seakeeping & Storage \\
\hline $\begin{array}{l}\text { Ability to trailer vehicle } \\
\text { by road Washington } \\
\text { State RCW }\end{array}$ & $\begin{array}{l}2.59 \mathrm{~m}(8.5 \mathrm{ft} .) \text { with } \\
\text { no permit }\end{array}$ & $\begin{array}{l}3.35 \mathrm{~m}(11 \mathrm{ft} .) \text { by permit } \\
4.27 \mathrm{~m}(14 \mathrm{ft} \text {.) with lead and chase vehicles }\end{array}$ \\
\hline $\begin{array}{l}\text { Operation on marine } \\
\text { fuels }\end{array}$ & $\begin{array}{l}\text { Marina docking } \\
\text { facilities }\end{array}$ & $\begin{array}{l}\text { Width is constrained at many facilities } \\
\text { Mooring costs increase with length }\end{array}$ \\
\hline
\end{tabular}

Once students selected their initial design requirements, they were able to create an initial weight and size estimate for their vehicle design. They then followed the design process outlined in Secrets of Tunnel Boat Design: ${ }^{4}$ 
1) Layout tunnel-hull dimensions

2) Estimate the aerodynamic lift

3) Estimate the aerodynamic drag

4) Estimate the sponson-pad (hull portion in contact with water) lift

5) Iterate sponson-pad lift to determine the wetted surface size

6) Calculate sponson-pad drag

7) Calculate appendage drag (propeller skeg, rudder)

8) Estimate the power requirement

9) Check vehicle stability

The following process is outlined for students, step by step. Students perform examples for each of the calculations. Students then create a spreadsheet to help them calculate performance and to track their design iterations. The first eight steps were covered in a one-week segment with three two-hour course sessions. The final stability check currently requires an additional week. The final step, constructing a physical prototype, has a due date delayed for one to two weeks from the date when the final design spreadsheet is due.

Table 3: An example weight estimate

\begin{tabular}{|l|l|l|l|l|l|l|}
\hline $\begin{array}{l}\text { 4 passengers, no } \\
\text { sleeping } \\
\text { accommodations }\end{array}$ & $\begin{array}{l}\text { Outboard } \\
224 \mathrm{~kW} \\
(300 \mathrm{hp})\end{array}$ & $\begin{array}{l}\text { Fuel } 454 \\
1(120 \\
\text { U.S. gal. })\end{array}$ & Hull & Battery & $\begin{array}{l}\text { Cargo, } \\
\text { Misc. }\end{array}$ & Total \\
\hline $\begin{array}{l}3558 \mathrm{~N} \\
(\sim 800 \mathrm{lbs} .)\end{array}$ & $2669 \mathrm{~N}$ & $\begin{array}{l}3363 \mathrm{~N} \\
(600 \mathrm{lbs} .)\end{array}$ & $\begin{array}{l}5348 \mathrm{~N} \\
(756 \mathrm{lbs} .)\end{array}$ & $\begin{array}{l}267 \mathrm{~N} \\
(60 \mathrm{lbs} .)\end{array}$ & $\begin{array}{l}4821 \mathrm{~N} \\
(1084 \mathrm{lbs} .)\end{array}$ & $\begin{array}{l}20016 \mathrm{~N} \\
(4500 \mathrm{lb} .)\end{array}$ \\
\hline
\end{tabular}

\section{Determining Initial Hull Dimensions}

A handout provided to students contains all variable/specification names and an example that illustrates how the parameters are used. Students create an initial hull layout or configuration. Only the parameters needed to estimate the basic lift and drag values are used and appear in Table 4 below.

Table 4: Initial hull values and parameters

\begin{tabular}{|l|l|l|l|l|l|}
\hline Name & $\begin{array}{l}\text { Values, } \\
\text { Units }\end{array}$ & Description & Name & Units & Description \\
\hline Chord, $c$ & $\begin{array}{l}6.1 \mathrm{~m} \\
(20 \mathrm{ft} .)\end{array}$ & $\begin{array}{l}\text { Distance from } \\
\text { leading edge to } \\
\text { trailing edge of wing }\end{array}$ & $\begin{array}{l}\text { Angle of } \\
\text { attack, } \alpha\end{array}$ & 4 degrees & $\begin{array}{l}\text { Positive angle of } \\
\text { wing between } \\
\text { tunnels above water }\end{array}$ \\
\hline $\begin{array}{l}\text { Wingspan, } \\
w\end{array}$ & $\begin{array}{l}3.05 \mathrm{~m} \\
(10 \mathrm{ft} .)\end{array}$ & $\begin{array}{l}\text { Distance between } \\
\text { tunnel sponsons }\end{array}$ & $\begin{array}{l}\text { Velocity, } \\
v\end{array}$ & $\begin{array}{l}96 \mathrm{kph}, \\
(60 \mathrm{mph}) \\
26.8 \mathrm{~m} / \mathrm{s}\end{array}$ & $\begin{array}{l}\text { Design operating } \\
\text { speed of vehicle }\end{array}$ \\
\hline $\begin{array}{l}\text { Airfoil } \\
\text { Thickness, }\end{array}$ & $\begin{array}{l}1.1 \mathrm{~m} \\
(3.6 \mathrm{ft} .)\end{array}$ & $\begin{array}{l}\text { Measurement of } \\
\text { thickest section of }\end{array}$ & Power, $P$ & $\begin{array}{l}224 \mathrm{~kW}, \\
(300 \mathrm{SHP})\end{array}$ & $\begin{array}{l}\text { Rated power of } \\
\text { prime mover- }\end{array}$ \\
\hline
\end{tabular}




\begin{tabular}{|l|l|l|l|l|l|}
\hline$t$ & & wing & & & engine or motor \\
\hline $\begin{array}{l}\text { Height } \\
\text { above } \\
\text { water, } H\end{array}$ & $\begin{array}{l}0.61 \mathrm{~m} \\
(2 \mathrm{ft} .)\end{array}$ & $\begin{array}{l}\text { Distance from water } \\
\text { to height of trailing } \\
\text { edge of wing }\end{array}$ & $\begin{array}{l}\text { Weight, } \\
\text { W }\end{array}$ & $\begin{array}{l}20016 \mathrm{~N} \\
(4500 \mathrm{lbs} .)\end{array}$ & $\begin{array}{l}\text { Total design weight } \\
\text { of vehicle with } \\
\text { fuel, passengers, } \\
\text { cargo }\end{array}$ \\
\hline $\begin{array}{l}\text { Wing Area, } \\
A \text { or } S A\end{array}$ & $18.6 \mathrm{~m} 2$ & $\begin{array}{l}\text { Span, } s c \text { chord } \\
\text { for non-tapered } \\
\text { wings }\end{array}$ & & & \\
\hline
\end{tabular}

\section{Estimating Aerodynamic Lift}

The overall vehicle weight is supported by both hydrodynamic lift and aerodynamic lift. The proportion of lift due to aerodynamic lift will increase with velocity. Students are introduced to the basic lift equation: $F_{\text {lift }}$ or Lift Aero $(L A$ in N or lbs. $)=1 / 2 \rho v^{2} C l A$ where $\rho=$ mass density of air (sea level for this project), $v=$ velocity, $C l=$ lift coefficient, and $A=$ the plan area of the wing. For this project, using non-tapered wings, $w * c=A$, plan area. Students are introduced to coefficient-of-lift versus angle-of-attack polar diagrams as available in Theory of Wings ${ }^{6}$ or JavaFoil. ${ }^{7}$ Standard polar diagrams assume an infinite wingspan. Data developed by Russell in a graph provides a base coefficient of lift, $C L A$, as a function of the angle of attack with lift curves for wings with a range of height-to-chord ratios. In addition to ground effect, this base coefficient of lift is modified for aspect ratio and wing thickness. Table 5 shows the related parameters and sample values:

Table 5: Parameters required to calculate aerodynamic lift ${ }^{8}$

\begin{tabular}{|l|l|}
\hline $\begin{array}{l}\text { Height of wing at chord midpoint, } \\
\text { from water surface, } h\end{array}$ & $\begin{array}{l}h=(H+1 / 2 * c * \sin \alpha) \\
0.822 \mathrm{~m}=\left(0.61 \mathrm{~m}+1 / 2 * 6.1 \mathrm{~m} * \sin 4^{0}\right)\end{array}$ \\
\hline Height-to-chord ratio, $h / c$ & $h / c=0.135=0.822 \mathrm{~m} / 6.1 \mathrm{~m}$ \\
\hline Wing aspect ratio, $w / c$ & $w / c=3.05 \mathrm{~m} / 6.1 \mathrm{~m}=0.5$ \\
\hline Thickness-to-chord ratio, $t / c$ & $t / c=1.1 \mathrm{~m} / 6.1 \mathrm{~m}=0.18$ \\
\hline Aspect Ratio Modification, $F A R$ & $F A R=4 * w / c$ \\
\hline Thickness Modification, $F T C$ & $F T C=0.45 / 0.07 * t / c$ \\
\hline Base Lift Coefficient, $C L A$ & $C L A \sim 0.55$ for $\alpha=4$ deg and $h / c=0.135$ \\
\hline Coefficient of Lift, $C l$ & $C l=C L A * F A R * F T C=0.55 * 2.0 * 1.157=1.273$ \\
\hline Lift Aero, Fla $\mathrm{N}$ or lbs. & $F l a=1 / 2 \rho v^{2} C l A=1 / 2 \rho v^{2} * 1.273 * 18.6=10.39 \mathrm{kN}$ \\
\hline
\end{tabular}




\section{Estimating Aerodynamic Drag}

For road-going vehicles, students are introduced to the total aerodynamic drag force as the product of dynamic pressure, $1 / 2 \rho v^{2}$, multiplied by the vehicle frontal area, $A$, and a coefficient of drag, $C d: F D A=1 / 2 \rho v^{2} C d A$. Sports car, road-going vehicles can range from a $C d$ of 0.31 to one of 0.41 with frontal areas of $1.72 \mathrm{~m}^{2}$ to $1.92 \mathrm{~m}^{2} .{ }^{9}$ Russell provides an opportunity to discuss aerodynamic normal forces, such as form drag, and viscous or parallel forces such as skin friction. ${ }^{10}$ For the tunnel-hull main wing, the total coefficient of drag is the sum of skin friction and induced drag. A skin friction drag coefficient, $C D O$, is named as a function of the thicknessto-chord ratio, $t / c$. The induced drag, $C D I$, is provided graphically as a function of the base-lift coefficient, CLA, with drag curves based on the height-to-chord ratio.

Table 6: Parameters required to calculate aerodynamic drag ${ }^{11}$

\begin{tabular}{|l|l|}
\hline Friction drag coefficient, $C D O$ & $\begin{array}{l}C D O=0.055 / 0.07 * t / c=0.055 / 0.07 * 0.18= \\
0.1414\end{array}$ \\
\hline Induced drag, $C D I$, based on $C L A$ and $h / c$ & $C D I=0.035$ \\
\hline Coefficient of drag, $C d$ & $C d=C D O+C D I=0.1414+0.035$ \\
\hline Aerodynamic drag due to main wing, $D A$ & $D A=1 / 2 \rho v^{2} C d \mathrm{~A}=1.44 \mathrm{kN}$ \\
\hline Lift to Drag Ratio, Fla/DA & $L / D=$ Fla/DA $=10.391 / 1.440=7.21$ \\
\hline
\end{tabular}

\section{Estimating Sponson-pad Lift, Wetted Surface and Drag}

Hydrodynamic lift is the difference between the total vehicle weight and the estimated aerodynamic lift. Initially, at rest, the tunnel boat is supported completely by buoyant forcesthe displacement of water due to hull volume and weight. As a vehicle's speed increases, its displacement force is replaced by a hydrodynamic force, and the tunnel boat is said to plane. As this occurs, the portion of the hull touching the water, the wetted surface, decreases. At higher speeds, a less wetted surface is required to support the hull. Sponson width, $b$, is fixed by the designer. As vehicle speed increases, the length of the hull touching the water, $l$, decreases. This increases the aspect ratio $b / l$ and improves the coefficient of lift of the sponson. As a result, the wetted surface area needed to support the hull decreases up until the limit of the balance of power and drag or until the vehicle becomes unstable. Calculations for hull wetted surface and the hydrodynamic lift force, $C l w$, are iterated at the vehicle's desired operating speed. The calculated hydrodynamic lift as a function of wetted surface and lift coefficient must match the difference between total vehicle weight and the estimated aerodynamic lift. 
Table 7: Sponson lift parameters ${ }^{12}$

\begin{tabular}{|l|l|}
\hline Hydrodynamic lift, $F l w$ & $F l w=$ Weight $-F l a=20.0 \mathrm{kN}-10.4 \mathrm{kN}=9.6 \mathrm{kN}$ \\
\hline Wetted surface area, $S w$ & $S w=2 * l * b=0.93 \mathrm{~m}^{2}$ Initial estimate \\
\hline Hull Sponson width, $b, \sim 610 \mathrm{~mm}$ & Wetted surface length (chord), $l_{\mathrm{sw}}, \sim 762 \mathrm{~mm}$ \\
\hline Aspect Ratio, sponson, $A R w=b / l=0.8$ & Mass density water, $\rho_{w}, 1000 \mathrm{~kg} / \mathrm{m}^{3}$ \\
\hline Sponson hull deadrise, $B D R, 10^{\circ}$ & Hull angle of attack, $\alpha_{w}=4^{\circ}$ \\
\hline$C l w=f n\left(\alpha_{\mathrm{w}}, A R w, B D R\right)$ & $S w$ (calculated) $=F l w /\left(1 / 2 \rho_{w} v^{2} C l w\right)$ \\
\hline
\end{tabular}

The hydrodynamic lift coefficient, $C l w$, is a function of the tunnel-sponson angle of attack, the aspect ratio of the sponson-hull width, $b$, to wetted surface length, $l$ (analogous to the chord for the wing), and the angle of the hull to the water surface, in a cross section perpendicular to the hull length, also known as the hull deadrise angle. An initial seed value for the total wetted surface, $S w$, double the wetted surface of each sponson, is selected. The wetted surface of each sponson is the product of wetted surface length $l$ and the hull width $b$. The hull designer initially sets the hull width, $b$. The total wetted surface area seed, $S w$, effectively sets the initial wetted hull length. The hydrodynamic coefficient of lift, $C l w$, is then estimated from a graph as a function of the hull angle of attack and the aspect ratio, $l / b$. Since the hydrodynamic support for the hull is already estimated, the newly estimated coefficient of lift, $C l w$, is used to calculate a new wetted surface area, $S w$. This process is repeated until the estimated surface area and the coefficient of lift converge, as approximated in Table 8 below.

Table 8: Example iterative estimation of wetted surface area, $S w$ and lift coefficient $C l w^{13}$

\begin{tabular}{|l|l|l|l|l|}
\hline $\begin{array}{l}S w, \mathrm{~m}^{2} \\
\text { Seed }\end{array}$ & $l_{\mathrm{sw}}, \mathrm{m}$ & $b / l$ & $C l w^{14}$ & $\begin{array}{l}S w, \mathrm{~m}^{2} \\
\text { Calculated }\end{array}$ \\
\hline 0.93 & 0.762 & 0.8 & 0.0387 & 0.69 \\
\hline 0.69 & 0.566 & 1.08 & 0.0438 & 0.61 \\
\hline 0.61 & 0.500 & 1.22 & 0.0463 & 0.58 \\
\hline 0.58 & 0.474 & 1.29 & 0.0475 & 0.56 \\
\hline
\end{tabular}




\begin{tabular}{|l|l|l|l|l|}
\hline 0.56 & 0.462 & 1.32 & 0.0480 & 0.56 \\
\hline 0.56 & 0.456 & 1.33 & 0.0483 & 0.55 \\
\hline
\end{tabular}

Hydrodynamic drag is a function of the friction drag, profile drag, and induced drag due to lift. ${ }^{15}$ Estimating friction drag, $C D F$, is a function of the product of the speed $v$ and wetted surface length $l_{\text {sw. }}$ In addition, a spray factor is used to account for additional drag resulting from a wetted surface that is sprayed onto the upper tunnel surface and the upper exterior hull surfaces above the waterline, estimated at 50 percent of the total friction drag. ${ }^{16}$ Induced drag, $C D I$, is a function of the angle of attack $\alpha_{\mathrm{w}}$ and the coefficient of lift, $C L W$. Profile drag is estimated at 0.0005 for tunnel-hull sponsons. ${ }^{17}$ The total hydrodynamic drag coefficient, $C D W$, is the sum of $C D F, C D I$ and $C D P$, as shown in Table 9.

Table 9: Calculations for sponson $\operatorname{drag}^{18}$

\begin{tabular}{|c|c|c|c|c|c|c|c|}
\hline $\begin{array}{l}l_{\mathrm{sw}} \\
\mathrm{m}\end{array}$ & $\begin{array}{l}v l, \\
\mathrm{~m}^{2} / \mathrm{s}\end{array}$ & $C D F 1^{19}$ & $\begin{array}{l}C D F= \\
C D F 1+ \\
C D F 1 * \\
\text { Spray }(0.5)\end{array}$ & $\begin{array}{l}C D I=C l w \\
* \\
0.0025 / 0.07\end{array}$ & $C D P$ & $\begin{array}{l}C D W= \\
C D F+ \\
C D I+ \\
C D P\end{array}$ & $\begin{array}{l}\text { Water Drag, } D W \\
=1 / 2 \rho_{\mathrm{w}} v^{2} C D W \\
S w, \mathrm{~N}\end{array}$ \\
\hline 0.462 & 12.4 & 0.00376 & 0.00564 & 0.001717 & 0.0005 & 0.007857 & $\sim 1.57 \mathrm{kN}$ \\
\hline 0.456 & 12.2 & 0.00378 & 0.00567 & 0.001727 & 0.0005 & 0.007897 & $\sim 1.57 \mathrm{kN}$ \\
\hline
\end{tabular}

The example values presented are based on interpolation and extrapolation of the graphs in Secrets of Tunnel Boat Design. ${ }^{20}$ In some cases, the graphs were interpolated using graphical means with a clear course plotter. In other cases, linearized equations were created and used to estimate what extrapolated graphs could be like for such things as the values of a lift coefficient for an aspect ratio beyond the range of given values. The selected sponson angle of attack, $4^{\circ}$, was chosen to achieve a nearly converging solution for the coefficient of lift and the wetted surface. This relatively high angle of attack, requiring a trim adjustment of the engine's thrust line, is the result of the relatively low velocity of the example. Software available from AeroMarine Research ${ }^{21}$ can be used to resolve these challenges and view vehicle performance through the velocity range. The calculation method shown provides an opportunity to discuss the risks and challenges associated with extrapolating and interpolating data.

Additional drag sources include the lower unit of the engine in the water, the aerodynamic drag of the upper power head of an outboard engine, and the aerodynamic drag of the cockpit. The book Secrets of Tunnel Boat Design groups engines into four categories to simplify estimates for engine lower-unit drag. ${ }^{22} \mathrm{~A}$ graph estimates lower-unit drag as a function of velocity. ${ }^{23}$ Coefficients of drag for the cockpit $\left(C d_{\mathrm{ap}}=0.3\right)$ and for an outboard engine cover $\left(C d_{\mathrm{ap}}=0.6\right)$ are provided as well. For this example, either twin racing outboards or a single stock outboard 
provides equivalent drag. Presumably, this cockpit provides a fairing for the engines as well. Otherwise, an additional drag calculation is performed for each outboard engine.

Table 10: Appendage drag calculations for the cockpit and the outboard-engine lower unit ${ }^{24}$

\begin{tabular}{|l|l|l|}
\hline Cockpit Cross Section Area, $S_{a p}$ & $S_{a p}=0.74 \mathrm{~m}^{2}$ & \\
\hline Cockpit Coefficient of Drag, $C d_{\mathrm{ap}}$ & $C d_{\mathrm{ap}}=0.3$ for faired cockpit & \\
\hline Cockpit Aerodynamic Drag, $D A P$ & $D A P=1 / 2 \rho v^{2} C d_{\mathrm{ap}} S_{\mathrm{ap}}=$ & $98 \mathrm{~N}$ \\
\hline $\begin{array}{l}\text { Lower unit drag, } D M, \text { group } 4 \\
\text { racing }\end{array}$ & $D M=$ & $178 \mathrm{~N}$ \\
\hline Total Appendage Drag, $D P$ & $D P=D M+D A P=$ & $276 \mathrm{~N}$ \\
\hline Water Drag, $D W$ & $D W=$ & $1791 \mathrm{~N}$ \\
\hline Aero Drag, $D A$ & $D A=$ & $1440 \mathrm{~N}$ \\
\hline Total Drag, $D T$ & $D T=D A+D W+D A P=$ & $3507 \mathrm{~N}$ \\
\hline Power required, $P$ & $P=D T * V$ & $98 \mathrm{~kW}$ \\
\hline Rate Power & $P=D T * V / 0.9$ & $109 \mathrm{~kW}$ \\
\hline
\end{tabular}

Once the total drag is known, the required power may be estimated. Secrets of Tunnel Boat Design assumes that 90 percent of the rated power is available as shaft power. ${ }^{26}$ For this example, a single $150 \mathrm{hp}$ engine would achieve the target speed and load. This might allow the proposed engine to be downsized or divided into two smaller units. The calculations could be run again with a higher speed.

\section{Stability Discussion}

A key difference between road-going vehicles and tunnel boats discussed with students is that the tunnel hull, similar to an aircraft, is designed to operate at a particular maximum velocity. In a road-going vehicle, power can be added to increase vehicle speed without losing vehicle stability, until fairly high rates of speed are attained. With a tunnel hull, the vertical force of the hull weight is balanced by the hydrodynamic lift near the rear of the hull and by aerodynamic lift. The aerodynamic-lift force is often located about one-third of the chord length from the leading edge near the front of the vessel. This depends upon the detailed shape of the airfoil and may be moved aft. As velocity increases, the center of the hydrodynamic lifting force moves aft while the aerodynamic lift force increases. Since the aerodynamic lift force is likely to be ahead of the center of gravity, a bow-up moment results in a rapidly increasing angle of attack. Many videos can be found to illustrate this behavior. One featuring the hydroplane Slo Mo Shun is particularly memorable. ${ }^{27}$ Modern hydroplanes attempt to address this challenge with a leading canard wing controlled by the driver. Many powerboats feature a hydraulic trim adjustment of 
the engine thrust. Since engine thrust is below the center of gravity, thrust itself leads to a bow up moment. Adjusting thrust levels and trim can reduce the bow up moment. In addition, the center of gravity location can be moved forward or aft to balance the moments caused by thrust, lift, and drag. This can occur for a designed velocity by repositioning passengers, storage, or fuel and batteries to adjust the center-of-gravity location. Secrets of Tunnel Boat Design explains a process with which to balance the moments at a designed speed. First, a center of gravity location is chosen, and then all of the moments for hydrodynamic lift (bow-down moment) and drag, engine thrust (bow up moment), and aerodynamic lift (bow-up moment) are calculated and

summed. ${ }^{28}$ The center of gravity location is then adjusted until the moments reach zero. Then the distances of the individual weight of the passengers, cargo, fuel, engines, and hull to the total center of gravity are adjusted until the static balance of moments about the center of gravity are zero. Students add these calculations to their spreadsheets. Although the calculations are straightforward, the concept of balancing forces around a proposed center of gravity location seems to pose more difficulty than the prior design analysis for lift and drag.

\section{Conclusion and Future Direction}

The tunnel-hull design project introduces students to the concepts of lift, drag, and thrust forces and the corresponding moments. Students construct a physical model as well. Since the physical models are constructed primarily of card stock, they are not durable enough to withstand our wind tunnel for $1 / 10$-scale models. As a result, the experimentation of different designs is completed numerically. We are currently building a wooden scale model that will be able to be tested in the wind tunnel and on water using a data acquisition system and an electric motor. In a subsequent course, students build and wind-tunnel test more durable physical car models - a future goal for this project as well. The project may be especially applicable to locations on the coast or near lakes and rivers, where a portion of students has boating experience. Opportunities to improve the project abound. Upper-division students could apply computational fluiddynamics tools to analyze a proposed design. Another goal is to combine low-cost rapid prototyping tools with an available 1/10th scale wind tunnel to study student designs. Scale models of the students' designs could be adapted for a radio-controlled option used to validate the design process. 


\section{References}

[1] E. Leonhardt, "The Ekranoplan Vehicle Design Project", Proceedings of the 2004 American Society for Engineering Education Annual Conference \& Exposition, Salt Lake City, Utah, June 2004.

[2] J. Russell, Secrets of Tunnel Boat Design (AeroMarine Research, 2006).

[3] "Frequently Asked Questions," Washington State Patrol, accessed February 11, 2017, http://www.wsp.wa.gov/information/faqs.htm\#vehclass.

[4] Russell, p. 133.

[5] “Specifications," Mercury Marine, accessed February 11, 2017, http://www.mercurygovsales.com/produ...p?productID=42.

[6] I. Abbott and A. von Doenhoff, Theory of Wing Sections (New York: Dover, 1959).

[7] M. Hepperle, “JavaFoil-Analysis of Airfoils,” JavaFoil (website), January 27, 2007, accessed February 11, 2017, http://www.mh-aerotools.de/airfoils/javafoil.htm.

[8] Russell, pp. 135-39.

[9] J. Katz, New Directions in Race Car Aerodynamics (Cambridge, MA: Bentley Publishers, 1995), p. 264.

[10] Russell, pp. 103-108.

[11] Russell, pp. 138-39.

[12] Russell, pp. 139-42.

[13] Russell, pp. 139-42.

[14] Russell, p. 159.

[15] Russell, p. 115.

[16] Russell, p. 143.

[17] Russell, p. 144.

[18] Russell, pp. 143-44.

[19] Russell, p. 160.

[20] Russell, pp. 157-61.

[21] Russell, pp. 208-10.

[22] Russell, p. 145.

[23] Russell, p. 161. 
[24] Russell, pp. 144-45.

[25] Russell, p. 161.

[26] Russell, p. 146.

[27] Thunderboats Video, "Slo-Mo-Shun V Flip," YouTube, January 15, 2015, accessed February 12, 2017.

[28] Russell, pp. 147-49. 